\title{
Transparência das Instituições Particulares de Solidariedade Social na Região Autónoma da Madeira: Estudo empírico
}

Transparency of Private Institutions of Social Solidarity in the Autonomous Region of Madeira: Empirical Study

Ana Maria Alves Bandeira bandeira@iscap.ipp.pt

Tomásia Ornelas

tomasia_pxo@hotmail.com

Deolinda Meira meira@iscap.ipp.pt

Graça Azevedo graca.azevedo@ua.pt 


\title{
Resumo
}

Por imposição legal, as Instituições Privadas de Solidariedade Social (IPSS) necessitam de reforçar as exigências da transparência relativamente às atividades que realizam e aos recursos que utilizam. As contas do exercício destas instituições obedecem ao regime da normalização contabilística para as Entidades do Setor Não Lucrativo, devendo ser publicadas obrigatoriamente no seu sítio institucional eletrónico até ao dia 31 de maio do ano seguinte a que dizem respeito (art. ${ }^{\circ} 14{ }^{\circ}$-A do Decreto-Lei n. $^{\circ}$ 172-A/2014, de 14 de novembro). O objetivo principal deste trabalho é o de analisar qual o nível de transparência das IPSS na Região Autónoma da Madeira (RAM). Para o efeito realizou-se um estudo empírico, tendo como população-alvo oitenta e cinco entidades, registadas naquela região e com o estatuto de IPSS. Metodologicamente, conjugaramse dois métodos de investigação, o método quantitativo e o método qualitativo para aferir o grau de transparência destas entidades na RAM. Os resultados mostraram que existem entidades que, mesmo tendo site, continuam a não publicar os seus relatórios de contas. É uma situação preocupante, uma vez que muitas das entidades não cumprem os requisitos legais impostos na última alteração dos seus Estatutos, com penalizações daí decorrentes, nomeadamente a suspensão dos apoios do Estado e a impossibilidade de celebrar acordos de cooperação.

Palavras-chave: Economia Social; Instituições Particulares de Solidariedade Social; Transparência; Entidades do Sector Não Lucrativo; Região Autónoma da Madeira.

\begin{abstract}
By legal imposition, Private Institutions of Social Solidarity need to strengthen the requirements of transparency regarding the activities they perform and the resources they use. The financial year accounts of these institutions comply with the accounting standardisation system for nonprofit organizations and must be published on their institutional website by 31 May of the following year to which they relate (article 14-A of Decree-Law 172-A/2014, of 14 November). The main objective of this study is to analyse the level of transparency of the Private Institutions of Social Solidarity in the Autonomous Region of Madeira (ARM). To this end, an empirical study was carried out, having as target population eighty-five entities, registered in that region and with the Private Institution of Social Solidarity status. Methodologically, two research methods were combined, the quantitative and the qualitative methods, to assess the degree of transparency of these organizations in the Autonomous Region of Madeira. The results showed that there are organizations that, despite having a website, still do not publish their annual reports. This is a worrying situation, since many of the organisations do not comply with the legal requirements imposed in the last amendment of their Statutes, with resulting penalties, namely the suspension of State support and the impossibility of signing cooperation agreements.
\end{abstract}

Keywords: Social Economy; Private Institutions of Social Solidarity; Transparency; Non-Profit Organizations; Autonomous Region of Madeira. 


\section{1.}

\section{Introdução}

$\mathrm{O}$ setor da economia social é um sector emergente e tem-se desenvolvido a uma grande escala em Portugal. Este setor consegue gerar auxílios, produzindo bens e prestando serviços em diversas áreas sociais, tanto a nível local, regional, nacional e internacional, construindo o bem-estar na sociedade (Ferreira, 2005).

De entre as entidades que integram o setor da economia social, neste estudo destacaremos aquelas que estão previstas no artigo $4 .^{\circ}$ do Decreto-Lei n. ${ }^{\circ}$ 120/2015, de 30 de junho (diploma que enquadra o "sector social $e$ solidário"), correspondendo ao conjunto das Instituições Privadas de Solidariedade Social (IPSS) ou legalmente equiparadas, definidas no artigo $1 .^{\circ}$ do Estatuto das IPSS (Ornelas, Bandeira \& Meira, 2017).

As IPSS foram durante muito tempo entidades que prestaram (e ainda prestam) auxílio à população mais desfavorecida, sendo, nos dias de hoje, um pilar fundamental no contexto das políticas sociais a que o Estado está obrigado (Oliveira, 2018).

Problema: As IPSS estão perante um problema relacionado com as alterações aos seus estatutos (Decreto-Lei n. ${ }^{\circ}$ 172-A/2014, de 14 de novembro), pois necessitam de reforçar as exigências da transparência relativamente às atividades que realizam e aos recursos que utilizam, devendo as contas ser publicadas obrigatoriamente no sítio institucional eletrónico da instituição até ao dia 31 de maio do ano seguinte a que dizem respeito (art. ${ }^{\circ} 14$. $^{\circ}$ A do Decreto-Lei n. ${ }^{\circ}$ 172-A/2014).

Objetivo: O objetivo principal deste estudo consiste em analisar se as IPSS da RAM estão a cumprir com as exigências legais em matéria de transparência e publicitação das contas (Ornelas, Bandeira \& Meira, 2017). Para a realização deste estudo, a população-alvo são as 85 entidades que têm Estatuto de IPSS e que estão registadas na RAM.
Metodologia: Para a obtenção dos resultados, são conjugados dois métodos de investigação: método quantitativo e método qualitativo (Ornelas, Bandeira \& Meira, 2017). O método quantitativo procede à identificação e apresentação dos dados a partir da amostra que é documentada, para, de seguida, realizar uma análise estatística, centrada nas hipóteses formuladas. $\mathrm{O}$ método qualitativo tem como finalidade desenvolver conceitos e descrever realidades, para isso utiliza as entrevistas, a observação direta e está atento ao contexto. Com base nesta metodologia, vamos responder às seguintes questões de investigação: (i) As IPSS da RAM têm sítio institucional eletrónico? (ii) As IPSS da RAM publicam as suas contas nesse sítio institucional eletrónico? (iii) Quais os tipos de contas que publicam?

(iv) Há quanto tempo é que publicam?

2.

\section{Enquadramento jurídico e contabilístico}

Nos termos da Lei de Bases da Economia Social (LBES) (Lei n. ${ }^{\circ}$ 30/2013, de 8 de maio), a noção de economia social está associada a um específico objeto social, traduzido no exercício de uma atividade económico-social, a qual terá por finalidade

"prosseguir o interesse geral da sociedade, quer diretamente quer através da prossecução dos interesses dos seus membros, utilizadores e beneficiários, quando socialmente relevantes".

Desta norma resulta que o legislador associa a noção de economia social a um específico objeto social, traduzido no exercício de uma atividade económico-social, a qual terá por finalidade a prossecução de um interesse geral por parte das entidades da economia social (n. ${ }^{\circ}$ 1 do art. $^{\circ} 2 .^{\circ}$ da LBES).

Este "interesse geral" prende-se não apenas com o facto de estas entidades prosseguirem fins sociais, surgindo como parceiros do Estado Social e cooperando com este na garantia de um mínimo vital de direitos 
económicos, sociais e culturais dos cidadãos, mas também com o seu peculiar modo de organização e funcionamento, distinto do setor público e do setor privado (Meira, 2013).

O setor da Economia Social é um setor que contribui para o crescimento sustentável, para a criação de emprego e para uma igualdade de distribuição dos rendimentos e da riqueza. Reúne em si todas as condições para poder ajustar tanto a rentabilidade, como a inserção social e os sistemas de governação democráticos, trabalhando em conjunto com os setores público e privado na prestação de serviços apropriados às necessidades dos seus membros e da comunidade (Monzón \& Chaves, 2012).

Em 2016 foi publicada a Conta Satélite da Economia Social 2013, um projeto desenvolvido pelo Instituto Nacional de Estatística em parceria com a Cooperativa António Sérgio para a Economia Social (CASES). Este projeto veio atualizar informações estatísticas relativamente a este setor, comparativamente com o ano de 2010, demonstrando o peso do mesmo em Portugal.

No universo de mais de 61 mil unidades de Economia Social, foram consideradas 5.584 entidades com o estatuto de IPSS ou equiparadas (cerca de 9\% do total), sendo estas maioritariamente constituídas por Associações com Fins Altruísticos (84,7\%), seguindo-se as Misericórdias (6,9\%), as Fundações (3,9\%), as Cooperativas $(2,4 \%)$ e as Associações Mutualistas (1,9\%).

As IPSS desenvolveram as suas atividades sobretudo nas áreas de ação e segurança social (76,4\% do total de IPSS), destacando-se ainda os cultos e as congregações $(8,0 \%)$ e a cultura, desporto e recreio $(6,4 \%)$.

Em 2013, as IPSS representaram 32,9\% da produção, $43 \%$ do $\mathrm{VAB}, \quad 44,1 \%$ das renumerações, $27,8 \%$ dos outros subsídios à produção e $60,4 \%$ do emprego remunerado da Economia Social.

Dado o contexto do Estado Social em que vivemos, este vê-se impedido de exercer algumas das suas competências na área social, sendo o setor da Economia Social, por intermédio das suas entidades, com particular destaque para as IPSS, a procurar soluções para muitos dos problemas sociais. Na maioria dos casos, assiste-se ao estabelecimento de relações de parceria entre o Estado e as entidades do setor da Economia Social, podendo falar-se a este propósito de verdadeiras parcerias público-sociais (Ornelas, Bandeira \& Meira, 2017).

Neste contexto, importa referir que as IPSS desempenham um papel relevante ao preencherem algumas das lacunas do Estado no que diz respeito às respostas sociais, construindo, em muitos casos soluções melhor adaptadas às necessidades da população do que as respostas estatais (Romão, 2002).

De acordo com o Decreto-Lei n. ${ }^{\circ}$ 172-A/2014, de 14 de novembro, e pela Lei n. $^{\circ} 76 / 2015$, de 28 de julho, as IPSS são

"pessoas coletivas, sem finalidade
lucrativa, constituídas exclusivamente
por iniciativa de particulares, com o
propósito de dar expressão organizada
ao dever moral de justiça e de
solidariedade, contribuindo para a
efetivação dos direitos sociais dos
cidadãos, desde que não sejam
administradas pelo Estado ou por outro
organismo público".

As IPSS podem ser de natureza associativa ou de natureza fundacional. As IPSS de natureza associativa podem ser: as Associações de Solidariedade Social, as Associações Mutualistas ou de Socorros Mútuos, as Fundações de Solidariedade Social, as Irmandades da Misericórdia, e respetivas, Uniões, Federações e Confederações (Santos, Lima \& Raimundo, 2011).

São de natureza fundacional: as Fundações de Solidariedade Social, os Centros Sociais Paroquiais e outros institutos criados por organizações da Igreja Católica ou por outras organizações religiosas, sujeitos ao regime das Fundações de Solidariedade Social.

As IPSS, de acordo com o art. ${ }^{\circ} 8^{\circ}$ do Estatuto das IPSS, também podem obter a natureza de 
Pessoas Coletivas de Utilidade Pública que são constituídas por

"associações ou fundações que
prossigam fins de interesse geral, ou da
comunidade nacional ou de qualquer
região ou circunscrição, cooperando
com a Administração Central ou a
Administração Local, em termos de
merecerem da parte desta
administração a declaração de
"utilidade pública".

As IPSS, conforme explica Alfaro (2003), "merecem, por parte da lei, uma proteção relevante, através do estabelecimento de um regime fiscal privilegiado específico", pois este regime beneficiário, vertido nos normativos fiscais traduz-se em quatro instrumentos jurídicos, isto é, existem quatro tipos de categorias em que abrange os benefícios destas instituições, principalmente, nos regimes específicos de não tributação, nas isenções de impostos e redução de taxas, na atribuição de benefícios fiscais específicos e, por último, no regime de obrigações acessórias menos exigentes.

Em termos de enquadramento contabilístico, as IPSS estão sujeitas ao normativo contabilístico designado de Normalização Contabilística para as Entidades do Sector Não Lucrativo (ESNL), regime esse que foi aprovado pelo Decreto-Lei n. ${ }^{\circ}$ 36-A/2011, de 9 de março.

Este diploma criou regras contabilísticas próprias para as entidades que, a título principal, detêm atividades sem fins lucrativos e que não podem redistribuir aos seus associados ou contribuintes qualquer lucro económico ou financeiro direto (Teixeira, 2014).

O regime contabilístico das ESNL é composto pelos seguintes instrumentos: Bases de Apresentação de Demonstrações Financeiras (BADF); Modelos de Demonstrações Financeiras; Código de Contas; Norma Contabilística e de Relato Financeiro para Entidades do Setor Não Lucrativo (NCRFESNL); e, Normas Interpretativas (conforme o n. ${ }^{\circ} 1.2$ do anexo II, do Decreto-Lei n. ${ }^{\circ}$ 36$\mathrm{A} / 2011$ ).
As BADF apresentam requisitos que permitem assegurar a comparabilidade da informação entre exercícios anteriores, assim como, a comparabilidade entre entidades diferentes que apresentam as demonstrações financeiras obrigatórias referidas no art. $^{\circ} 11 .^{\circ}$ do DecretoLei referido anteriormente (Ornelas, Bandeira $\&$ Meira, 2017).

Assim, as IPSS necessitam de reforçar as exigências da transparência relativamente às atividades que realizam e aos recursos que utilizam, sobretudo através da obrigação de prestarem informação confiável sobre a gestão dos recursos que lhes são confiados, bem como sobre os resultados alcançados no desenvolvimento das suas atividades.

Nesta conformidade, o novo estatuto veio estabelecer um conjunto de regras de publicitação das contas, que vai de encontro ao que está previsto na BADF no que se refere à transparência ( art. $^{\circ} 14 .^{\circ}-\mathrm{A}$, n. $^{\circ} 2$ do Decreto-Lei n. ${ }^{\circ}$ 172-A/2014), devendo as contas ser publicadas obrigatoriamente no seu sítio institucional eletrónico até ao dia 31 de maio do ano seguinte a que dizem respeito.

O mesmo artigo descreve que as contas só são aprovadas pelos respetivos órgãos nos termos estatutários e, as mesmas devem ser apresentadas ao órgão competente para a verificação da sua legalidade. Este órgão, por sua vez, será o membro do Governo responsável pela área da Segurança Social.

Os incumprimentos destas obrigações têm consequências gravosas para as entidades, pois poderá implicar que o órgão de administração seja chamado a apresentar um programa adequado ao restabelecimento da legalidade e do equilíbrio financeiro.

Se este programa não for apresentado ou não for aprovado, de acordo com o art. $^{\circ} 35 .^{\circ}$ do Estatuto das IPSS, o órgão competente pode requerer judicialmente a destituição do órgão de administração.

É de referir que o $\operatorname{art}^{\circ}{ }^{\circ} 34 .^{\circ}$ trata da fiscalização destas entidades e, consagra que

"O Estado, através dos seus órgãos e serviços competentes (..) exerce os 
poderes de inspeção, auditoria e fiscalização sobre as instituições (...) podendo para o efeito ordenar a realização de inquéritos, sindicâncias e inspeções".

Conforme Meira (2013) explica, a expressão "O Estado apoia" significa que as entidades irão beneficiar de um apoio público para que as mesmas consigam prosseguir os seus fins sociais, surgindo como parceiros do Estado Social. Estas entidades cooperam com o Estado na garantia de um mínimo vital de direitos económicos, sociais e culturais dos cidadãos.

$\mathrm{O}$ relacionamento entre as duas partes estruturou-se da seguinte forma: o Estado fica com as funções de regulação e cofinanciamento das atividades destas entidades. Por sua vez, as IPSS são responsáveis pela produção de serviços nas áreas de apoio à infância e à terceira idade e no apoio às pessoas portadoras de deficiência, privilegiando nessas atividades as pessoas de menores rendimentos. A finalidade da cooperação consiste na

"concessão de prestações sociais e baseia-se no reconhecimento $e$ valorização, por parte do Estado, do contributo das instituições para a realização dos fins de ação social, enquanto organizada da sociedade civil" (Despacho Normativo 75/92, Norma II).

A cooperação pode assumir, nomeadamente, as seguintes formas: a) Acordo de cooperação; b) Acordo de gestão; c) Protocolo; ou, d) Convenção.

Assim, propusemo-nos realizar este estudo com o objetivo de analisar se as IPSS estão a cumprir com as exigências legais decorrentes da recente alteração aos seus Estatutos, em matéria de transparência e publicitação das contas (Ornelas, Bandeira \& Meira, 2017).

Esta questão surge para alertar as IPSS para este problema, porque se não forem cumpridas tais obrigações, as IPSS ficam sujeitas a suspensão dos apoios do Estado e a impossibilidade de celebrar os acordos de cooperação.

Para tal realizou-se um estudo empírico, no qual se procedeu à averiguação de qual o nível de transparência das IPSS na Região Autónoma da Madeira (RAM), que se apresenta na secção seguinte.

3.

Estudo Empírico-Averiguar o nível de transparência das IPSS na RAM

Como já referido, este estudo recorreu a uma metodologia de natureza quantitativa, através da técnica análise de rácios, bem como de natureza qualitativa, através da técnica de análise de conteúdo.

O método quantitativo é um método que prevê a elaboração de um plano de investigação no qual são definidos os procedimentos e as finalidades da investigação. Assim, começouse por identificar e apresentar os dados a partir da amostra selecionada, para, deste modo, realizar uma análise estatística centrada nas questões de investigação. Para o tratamento dos dados estatísticos utilizou-se o Microsoft Excel.

A principal finalidade do método qualitativo é descrever realidades múltiplas e desenvolver conceitos sensíveis. Para este método utilizouse técnicas como a observação direta e a recolha de dados, através da análise documental e da análise de conteúdo.

A análise dos dados desenvolve-se em três etapas: descrição, análise e interpretação. A descrição corresponde à escrita de textos dos dados originais mencionados pelo investigador. A análise tem como objetivo a organização dos dados, onde se devem demonstrar os aspetos essenciais para proporcionar a obtenção de respostas ao problema proposto pelo estudo. Por último, a interpretação procura dar sentido mais amplo das respostas, mediante a sua ligação a outros conhecimentos obtidos anteriormente (Gil, 2008). 
Por conseguinte, a análise de dados do trabalho recai sobre uma das técnicas mais utilizadas nas ciências sociais: a análise de conteúdo, que permite viabilizar a descrição do conteúdo de comunicação (Pacheco, 2006).

Face ao exposto, são apresentadas as questões de investigação que procuram responder ao objetivo inicialmente referido:

Q1. As IPSS da RAM têm sítio institucional eletrónico?

Q2. As IPSS da RAM publicam as suas contas nesse sítio institucional eletrónico?

Q3. Quais os tipos de contas que publicam?
Q4. Há quanto tempo é que publicam?

Para este estudo, a população-alvo que teremos por base serão as IPSS da RAM, contabilizando-se 85 entidades com o estatuto de IPSS ${ }^{1}$.

Os resultados que irão ser apresentados foram obtidos através das informações disponibilizadas nos sites de algumas entidades dos diversos conselhos da RAM, da comunicação via eletrónica e telefónica ${ }^{2}$.

$\mathrm{Na}$ figura 1, podemos verificar a distribuição das IPSS pelos concelhos da RAM.

Figura 9 - Número de IPSS por concelhos da RAM

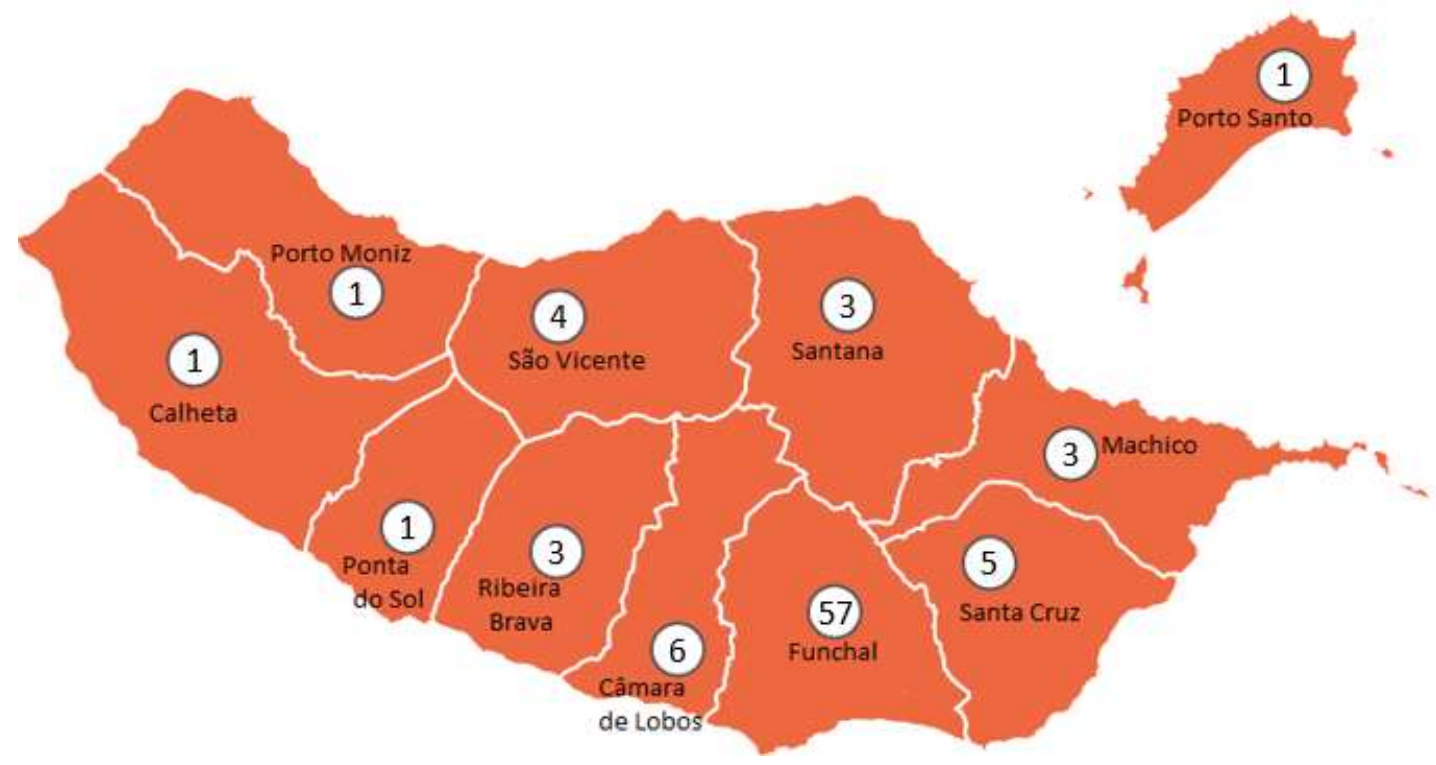

Fonte: Dados à data de 7 de setembro de 2018. Elaboração própria.

Verificou-se que o concelho do Funchal é aquele onde existe maior concentração, com 57 entidades registadas como IPSS. Os concelhos do Porto Santo, Porto Moniz, Ponta do Sol e Calheta são os concelhos onde foram registadas apenas uma IPSS. Assim, foi possível verificar que não existe uma distribuição uniforme pelos concelhos em geral, uma vez que o Funchal é o concelho mais importante da RAM.

O gráfico seguinte representa a forma jurídica com que as IPSS foram registadas na RAM. 
Gráfico 1 - Forma Jurídica de como as IPSS estão registadas na RAM

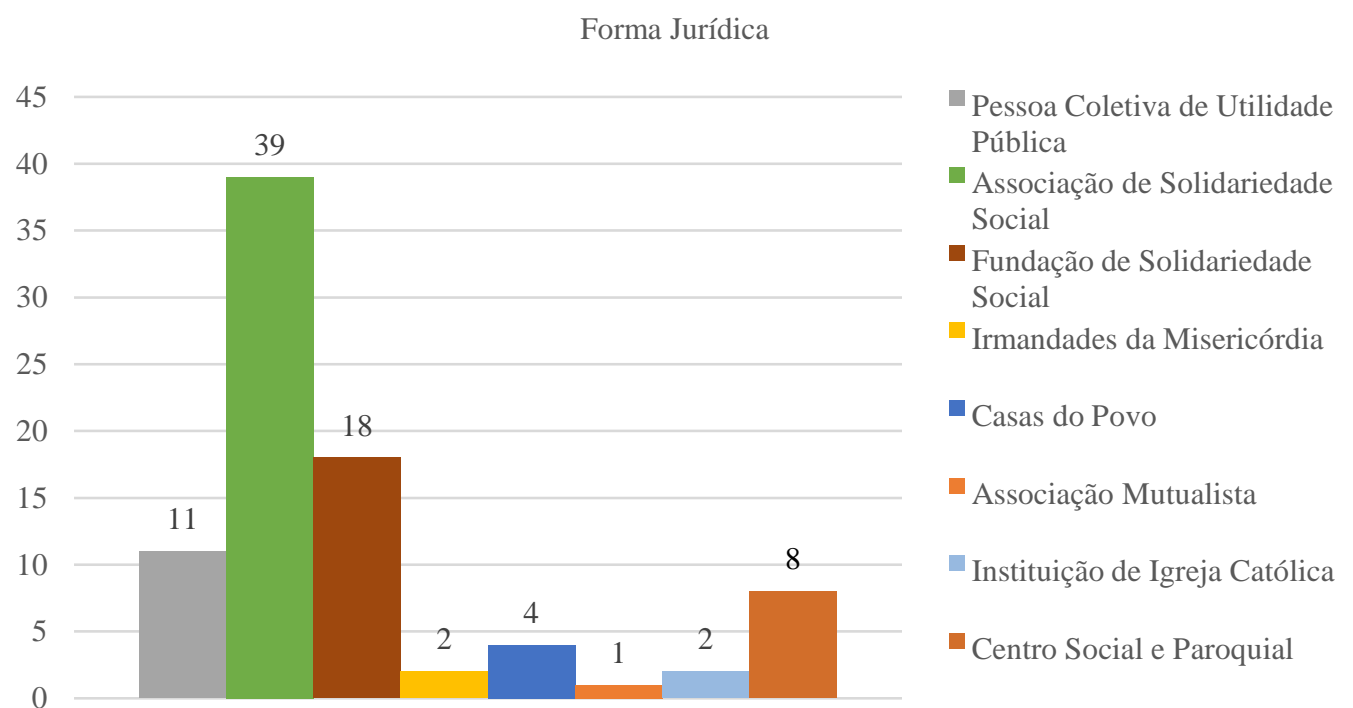

Fonte: Dados à data de 7 de setembro de 2018. Microsoft Excel - elaboração própria.

Podemos verificar que existe uma maior concentração de IPSS que detêm a forma de Associação de Solidariedade Social, contabilizando-se 39 entidades. As formas jurídicas com menos entidades são as Associações Mutualistas (1), as Instituições de
Igreja Católica (2), as Irmandades da Misericórdia (2) e as entidades que estão registadas como Casas do Povo (4).

De seguida, na tabela 1 observamos as atividades que as entidades desenvolvem.

Tabela 7 - Setor de Atividades em que as IPSS atuam na RAM

Setor de Atividade

\begin{tabular}{|c|c|}
\hline Ação Social da Igreja & 3 \\
\hline Apoiar as Vítimas do Crime de Violência Doméstica & 1 \\
\hline Apoio a Crianças e Jovens & 10 \\
\hline Apoio a Crianças e Idosos & 1 \\
\hline Apoio a Crianças, Jovens e Idosos & 8 \\
\hline Apoio a Idosos & 9 \\
\hline Apoio a Pessoas Infetadas e Afetadas pelo VIH & 1 \\
\hline Apoio a Pessoas Infetadas e Afetadas pelo Alcoolismo & 1 \\
\hline Apoio ao Doente Oncológico e Família & 2 \\
\hline Área da Saúde Mental & 4 \\
\hline Assistência a Crianças Desprotegidas & 2 \\
\hline Assistência Humanitária e Social & 1 \\
\hline Centro de Apoio à Vida & 1 \\
\hline Dádiva de Sangue & 1 \\
\hline Distribuição Alimentar & 2 \\
\hline Inclusão Social & 28 \\
\hline Projetos de Intervenção Social Intergeracional & 2 \\
\hline Promoção e Divulgação da Cultura Africana & 1 \\
\hline Promoção e Divulgação do Voluntariado & 1 \\
\hline Reconhecimento da Doença de Alzheimer & 1 \\
\hline Segurança Social e Saúde & 5 \\
\hline
\end{tabular}

Fonte: Dados à data de 7 de setembro de 2018. Microsoft Excel - elaboração própria.

Foi possível apurar que a maioria das IPSS atuam na área da Inclusão Social, existindo 28 entidades que se preocupam em envolver a população desfavorecida na comunidade. 
Podemos observar na mesma tabela que há determinadas entidades que apenas trabalham numa área. Aponte-se o exemplo da atividade de "Apoio as Vítimas do Crime de Violência Doméstica", que é apenas trabalhada pela Associação Presença Feminina-FEM, ou seja, esta é a única entidade que se preocupa em ajudar e a defender as pessoas que são vítimas de violência doméstica.

No que diz respeito ao número de trabalhadores, das 85 entidades apenas 53 disponibilizaram a informação, em que existe cerca de 1500 pessoas que estão a trabalhar nas IPSS da RAM, ou seja, cerca de $62 \%$ das entidades emprega 1500 pessoas, que podem variar entre ter 1 funcionário a 153 funcionários por entidade.

Em relação ao número de voluntários, $62 \%$ das IPSS têm, normalmente, 2278 voluntários, valor esse que pode variar entre 1 voluntário a 1000 voluntários, e que podem também variar ao longo do ano, pois existe meses que há mais voluntários do que outros. Também podemos afirmar que muitos dos voluntários são titulares dos órgãos de administração da própria IPSS (informação essa que foi disponibilizada aquando do contacto via telefone ou eletronicamente ou presencialmente).

Após esta breve caracterização da amostra, de seguida passaremos a responder as questões de investigação colocadas inicialmente.

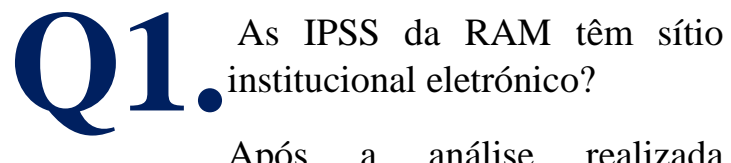
verificamos que o ponto de situação relativamente às IPSS com sítio institucional era o seguinte.

Gráfico 2 - Percentagem de IPSS com sítio institucional eletrónico na RAM

\section{As IPSS apresentam sítio institucional eletrónico?}

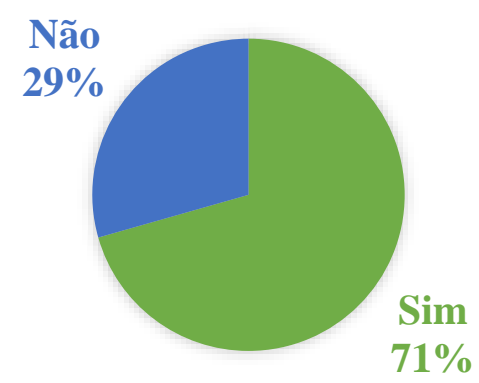

Fonte: Dados à data de 7 de setembro de 2018. Microsoft Excel - elaboração própria.

Como podemos observar, $71 \%$ das entidades registadas como IPSS possuem sítio institucional eletrónico, ou seja, 60 entidades tiveram a preocupação em criar um site após a entrada em vigor do novo estatuto, cumprindo assim com os seus deveres enquanto IPSS, continuando com os seus acordos de cooperação com o Estado.

Por sua vez, $29 \%$ das entidades ainda não criaram o seu sítio institucional eletrónico para assim cumprirem com as suas obrigações estatutárias e, portanto, poderão sofrer penalizações gravosas, como a destituição do órgão de administração.

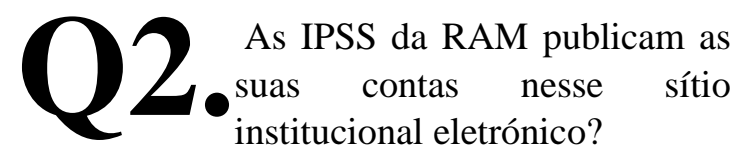


Gráfico 3 - Percentagem de IPSS que possuem um sítio institucional eletrónico e que publicam as contas nesse mesmo site

Das IPSS que possuem site, qual a percentagem das que publicam as suas contas?

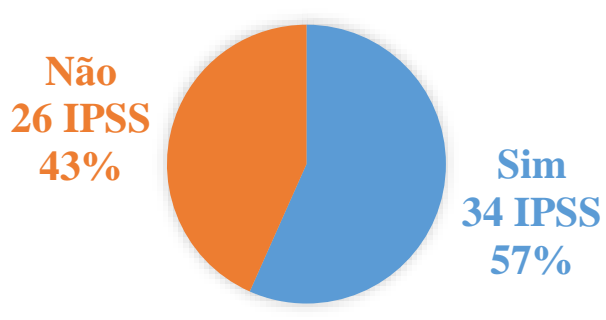

Fonte: Dados à data de 7 de setembro de 2018. Microsoft Excel - elaboração própria.

Por sua vez, no gráfico 3 observamos que, apesar das 60 entidades $(71 \%$ - gráfico 2$)$ possuírem sítio institucional eletrónico, existem 26 IPSS que não publicaram os seus Relatórios e Contas no site, ficando, deste modo, sujeitas às consequências gravosas que mencionamos anteriormente.

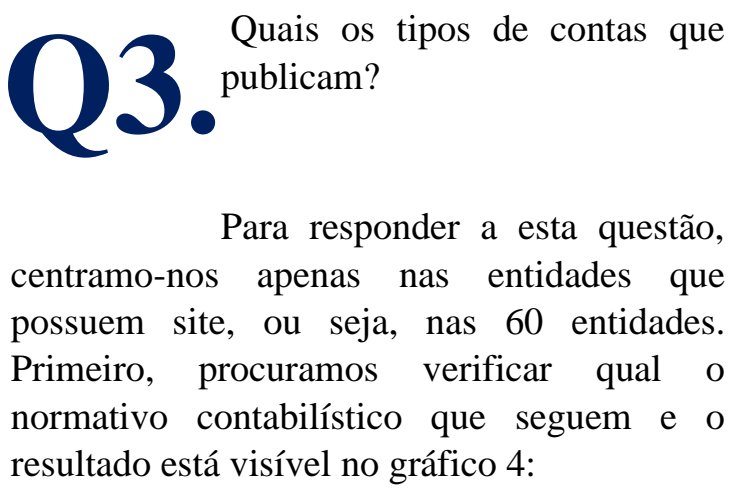

Gráfico 4 - Qual o normativo contabilístico que as IPSS seguem?

\section{Qual o normativo contabilístico que as IPSS utilizam?}

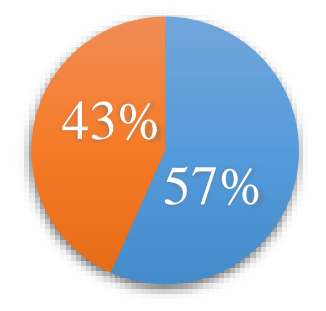

Fonte: Dados à data de 7 de setembro de 2018. Microsoft Excel - elaboração própria.

Podemos afirmar que todas as IPSS que publicaram as suas contas nos seus sites, isto é, as 34 entidades, publicaram as suas contas de acordo com o regime da normalização contabilística para as ESNL (Decreto-Lei . $^{\circ}$ 36-A/2011, de 9 de março), cumprindo assim com as regras contabilísticas que são aplicáveis especificamente a estas entidades.

$\mathrm{O}$ atual normativo contabilístico permite apresentar de forma adequada a posição financeira, o desempenho financeiro e os fluxos de caixa da instituição, bem como, faz a 
sua própria avaliação financeira de forma geral, Soares (2015) e Bandeira (2013).

De seguida mostramos o gráfico 6 onde está exposto as percentagens dos tipos de contas que as IPSS publicaram no seu sítio

Gráfico 5 - Percentagem dos tipos de contas que as IPSS publicaram nos seus sites

\section{Qual o tipo de contas que as entidades publicam no seu site?}

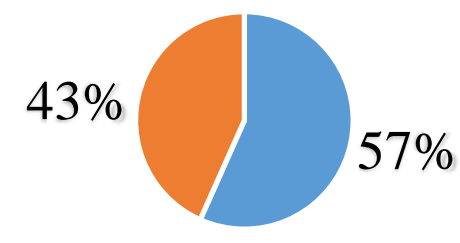

- Relatório de Contas

- Não Apresentam

Fonte: Dados à data de 7 de setembro de 2018. Microsoft Excel - elaboração própria.

Assim, podemos afirmar que as 34 entidades (57\% das entidades) cumprem com os requisitos definidos pelo art. ${ }^{\circ} 11 .^{\circ}$ do DecretoLei n. ${ }^{\circ} 36-\mathrm{A} / 2011$, de 9 de março, ou seja, as IPSS que publicaram os seus Relatórios de Contas apresentaram as seguintes demonstrações financeiras: o Balanço, a Demonstração dos resultados por naturezas ou por funções, a Demonstração dos fluxos de caixa e o Anexo.

Q4. Há quanto tempo é que publicam as contas?

Neste último gráfico (gráfico 6) pode-se verificar que existem 15 entidades que publicam as suas contas há dois anos no seu site, enquanto que uma entidade publica há sete anos.
Podemos afirmar que, com esta nova implementação, as IPSS tiveram o cuidado de publicar recentemente as suas contas, apesar de existir uma entidade que publica há sete anos consecutivos.

Assim, em nome do princípio da transparência, as entidades que publicam há mais de 2 anos consecutivos estão a cumprir com os seus deveres legais enquanto ESNL, pois publicam as suas contas até ao dia 31 de maio do ano seguinte a que dizem respeito.

Aquelas oito entidades que apenas publicam há um ano estão em situação de incumprimento legal, podendo vir a sofrer alguma penalização do Governo.

Gráfico 6 - O número de anos que as IPSS publicam as contas no site 


\section{O número de anos que publicam as contas no site}

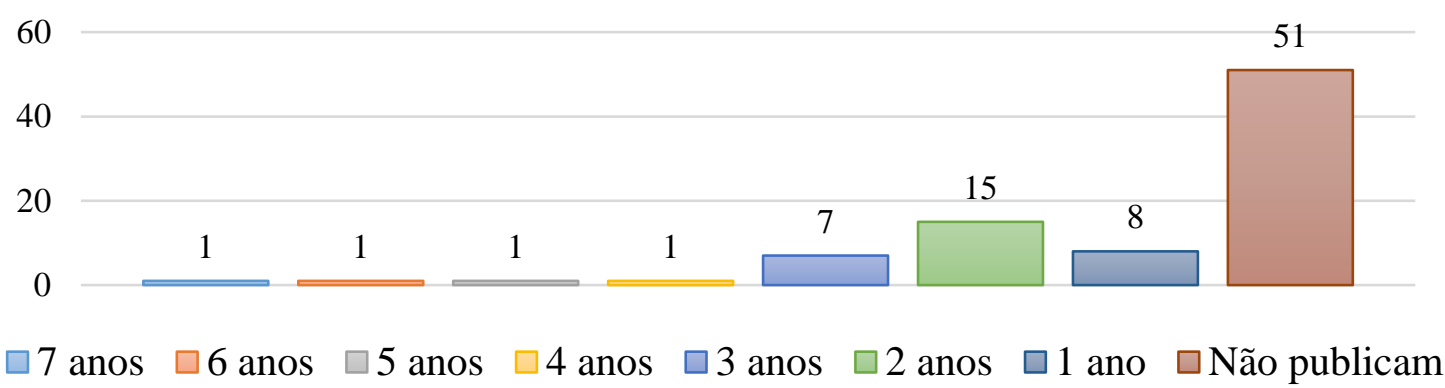

Fonte: Dados à data de 7 de setembro de 2018. Microsoft Excel - elaboração própria.

4.

\section{Considerações finais}

As IPSS viram as suas obrigações serem profundamente alteradas com a aprovação do novo Estatuto (Decreto-Lei n. ${ }^{\circ} 172-\mathrm{A} / 2014$, de 14 de novembro). Este documento visa que estas entidades sejam mais transparentes, mostrando aos interessados a origem e o destino dos seus recursos, divulgando a sua informação financeira e económica através de um sítio na internet.

Os resultados do estudo indicam que $71 \%$ das IPSS (60 entidades) possuem o seu próprio sítio institucional eletrónico, ou seja, cumprem com os seus deveres enquanto IPSS.

Verificou-se que dessas 60 entidades que possuem site, apenas 34 IPSS é que publicaram os seus Relatórios de Contas, seguindo o regime da normalização contabilística para as ESNL.

Assim, podemos afirmar que, no conjunto das entidades que apresentam os relatórios, existe uma uniformidade quanto à sua forma de relato financeiro, ou seja, não há uma grande diversidade de modelos, indicando uniformidade e harmonização nos relatórios apresentados nos sites.

Apenas estas 34 entidades estão em condições de dar cumprimento à exigência legal obrigatória de publicitação das contas do exercício no sítio institucional eletrónico da instituição até 31 de maio do ano seguinte a que dizem respeito (art. ${ }^{\circ}$ 14. ${ }^{\circ}$-A do Estatuto das IPSS).

As 26 entidades que não apresentaram as suas contas até maio de 2018, relativamente ao ano de 2017, no seu sítio institucional eletrónico, não estão a cumprir com os requisitos legais, nomeadamente do seu Estatuto e, portanto, poderão sofrer consequências gravosas.

Conclui-se com esta investigação que apesar de haver IPSS a publicar as suas contas nos seus sites, existe ainda uma elevada taxa de incumprimento e, por conseguinte, estas IPSS poderão ser penalizadas, nomeadamente com a suspensão dos apoios do Estado, a impossibilidade de celebrar os acordos de cooperação entre as IPSS e o Estado bem como a destituição do órgão de administração.

Este estudo realizado pode dar um contributo muito importante para as entidades da RAM, na medida em que: (i) Permite contribuir para a literacia das entidades da economia social, tanto numa perspetiva jurídica bem como contabilística; (ii) Alertar para a importância das mesmas na sociedade em que estão inseridas; e, (iii) Sensibilizar a entidade para a necessidade de cumprir com a sua obrigatoriedade quanto a publicação das suas demonstrações financeiras no seu sítio institucional eletrónico, para assim continuar com os seus acordos de cooperação com o Estado. 
No seguimento do trabalho realizado importa referir as limitações referentes ao acesso à informação, pois não existem bases de dados com informação das entidades estudadas. Outra limitação é a escassez de estudos desta natureza, a sua falta impossibilita a possibilidade de comparar e validar o estudo aqui desenvolvido.

$\mathrm{Na}$ perspetiva deste trabalho, aqui desenvolvido, poder ser complementado no futuro, sugere-se a análise do impacto que o incumprimento, por parte das IPSS, pode causar nos empregos bem como nas externalidades positivas e negativas junto das comunidades em que se inserem. Outro aspeto que poderá ser analisado em investigação futura é a análise de qual, ou quais, as penalidades que estas entidades podem estar sujeitas por não cumprirem com os normativos em vigor e quais os impactos dessas penalidades na sua própria sustentabilidade. 
Alfaro, M. (2003), "O Regime Fiscal das IPSS", Revista de Doutrina Tributária, $1^{\circ}$ e $2^{\circ}$ trimestre de 2003.

Bandeira, A. (2013). "O Regime de Normalização Contabilística para as empresas do setor não lucrativo - SNC - ESNL - e as suas especificidades relativamente ao Relato Financeiro", Revista Cooperativismo e Economia Social, $n^{\circ}$ 58, ISSN: 1130-2682, University of Vigo, pp. 223-230.

Ferreira, R. (2005), “As Instituições do Terceiro Setor”, Revista OTOC nº 71, p. 30-35.

Gil, A. (2008), Como elaborar projetos de pesquisa, São Paulo: Atlas.

Meira, Deolinda Aparício (2013), “A Lei de Bases da Economia Social Portuguesa: do projeto ao texto final”, CIRIEC-España, revista jurídica de economia social y cooperativa, n. $^{\circ} 243$, p. 21-52.

Monzón, J., \& Chaves, R. (2012), A Economia Social na União Europeia, Bruxelas: Síntese do relatório elaborado a pedido do Comité Económico e Social Europeu pelo Centro Internacional de Pesquisa e Informação sobre Economia Pública, Social e Cooperativa (CIRIEC).

Oliveira, P. (2018), IPSS são pilar incontornável do Estado Social em Portugal, Consultado em Junho de 2018 em: www.solidariedade.pt/site/detalhe/13202.

Ornelas, T., Bandeira, A., \& Meira, D. (2017), Transparência das IPSS na Região Autónoma da Madeira: estudo empírico, XVI Congresso Internacional de Contabilidade e Auditoria, Ordem dos Contabilistas Certificados, Universidade de Aveiro.

Pacheco, J. (2006), Currículo, Investigação e Mudança, In. L. Lima, J. Pacheco, M. Esteves, \& R. Canário, A educação em Portugal (1986-2006) Alguns contributos de investigação, Porto: Sociedade Portuguesa de Ciências da Educação.

Romão, F. (2002), Metodologia de Desenvolvimento de um sistema de Informação para uma Instituição Particular de Solidariedade Social, Universidade de Aveiro, Aveiro. 
Santos, J., Lima, R., \& Raimundo, J. (2011), “Norma Contabilística e Relato Financeiro para Entidades do Setor Não Lucrativo (NCRF-ESNL)", Manual OTOC.

Soares, C., (2015), A Demonstração dos Fluxos de Caixa nas Instituições Particulares de Solidariedade Social, Dissertação de Mestrado, ISCAP, Porto.

Teixeira, Z. (2014), O Relato Financeiro nas IPSS: Estudo de caso de uma IPSS do concelho de Vila Nova de Gaia, Dissertação de Mestrado, ISCAP, Porto.

\section{Legislação}

Decreto-lei n. ${ }^{\circ}$ 172-A/2014, de 14 de novembro, Diário da República n. ${ }^{\circ} 221$ - 1. a série, Ministério da Solidariedade, Emprego e Segurança Social, Procede à quinta alteração ao Decreto-Lei n. ${ }^{\circ}$ 119/83, de 25 de fevereiro, 5882-(2)5882-(26), Lisboa.

Decreto-Lei n. ${ }^{\circ}$ 36-A/2011, de 9 de março, Diário da República n. ${ }^{\circ} 48$ - 1. ${ }^{\text {a }}$ série, Ministério das Finanças e da Administração Pública, Aprovação do regime da normalização contabilística para as entidades do sector não lucrativo (ESNL), 1344-(2)-1344(11), Lisboa.

Despacho Normativo 75/92, de 20 de maio, que estabelece normas reguladoras de cooperação entre os "centros regionais de segurança social" e as instituições particulares de solidariedade social.

Lei n. ${ }^{\circ}$ 30/2013, de 8 de maio, Diário da República n. ${ }^{\circ} 88-1$. $^{\text {a }}$ série, que aprova a Lei de Bases da Economia Social, 2727-2728, Lisboa.

Lei n. ${ }^{\circ} 76 / 2015$, de 28 de julho, Diário da República n. ${ }^{\circ} 145$ - 1. ${ }^{\text {a }}$ série, Assembleia da República, primeira alteração ao Decreto-Lei n. ${ }^{\circ}$ 172-A/2014, de 14 de novembro e sexta alteração ao Estatuto das Instituições Particulares de Solidariedade Social, por apreciação parlamentar, 5051-5052, Lisboa. 